\title{
Papers
}

\section{Costs and effectiveness of community postnatal support workers: randomised controlled trial}

\author{
C Jane Morrell, Helen Spiby, P Stewart, S Walters, A Morgan
}

\begin{abstract}
Objectives To establish the relative cost effectiveness of postnatal support in the community in addition to the usual care provided by community midwives. Design Randomised controlled trial with six month follow up.

Setting Recruitment in a university teaching hospital and care provided in women's homes.

Participants 623 postnatal women allocated at random to intervention (311) or control (312) group. Intervention Up to 10 home visits in the first postnatal month of up to three hours duration by a community postnatal support worker.

Main outcome measure General health status as measured by the SF-36 and risk of postnatal depression. Breast feeding rates, satisfaction with care, use of services, and personal costs.

Results At six weeks there was no significant improvement in health status among the women in the intervention group. At six weeks the mean total NHS costs were $£ 635$ for the intervention group and $£ 456$ for the control group $(\mathrm{P}=0.001)$. At six months figures were $£ 815$ and $£ 639(\mathrm{P}=0.001)$. There were no differences between the groups in use of social services or personal costs. The women in the intervention group were very satisfied with the support worker visits.

Conclusions There was no health benefit of additional home visits by community postnatal support workers compared with traditional community midwifery visiting as measured by the SF-36. There were no savings to the NHS over six months after the introduction of the community postnatal support worker service.
\end{abstract}

\section{Introduction}

The extent of enduring physical and psychological morbidity after childbirth and the potential consequences for infants may be unrecognised by health professionals. ${ }^{1-3}$ Although the effectiveness of elements of traditional postnatal care has been questioned, ${ }^{4}$ the importance of emotional support for women after childbirth has been emphasised. ${ }^{5}$ While the total annual cost of maternity care in England and Wales is around $£ 1.1$ billion, there is little evidence of the appropriateness, clinical effectiveness, or efficiency of the care provided. ${ }^{6}$
There is increasing evidence of the beneficial effect of social support on health during pregnancy and labour and in encouraging successful breast feeding. ${ }^{7-9}$ It may also help in the treatment of postnatal depression..$^{10}$ In the Netherlands, a maternity aide provides care in the woman's home postnatally, ${ }^{11}$ but in the United Kingdom there is no model offering similar postnatal support.

We undertook a randomised controlled trial to assess whether additional postnatal support provided by trained community postnatal support workers could have a positive effect on women's general health and cost savings to the NHS.

\section{Methods}

Study population-The trial was approved by the local research ethics committee, and women were recruited on postnatal wards from October 1996 to November 1997. The planned trial population was women aged 17 years or over who delivered a live baby and lived in the area served by community midwives at the recruiting hospital. Information on the trial was given to women from the 32nd week of pregnancy. Women who could not give informed consent or communicate in English or who had a baby in the special care baby unit for more than 48 hours were excluded.

Intervention-The planned postnatal intervention aimed to help women rest and recover after childbirth. Midwives were involved in formulating the intervention and defining the support workers' role and their eight week training programme. This aimed to enable the support workers to provide effective practical and emotional support, including helping the mother gain confidence in caring for her baby and reinforcing midwifery advice on infant feeding. The support workers achieved their national vocational qualification (level 2) postnatal care award and completed endorsement units accredited to the domiciliary care award and competence in the care of young children. All women in the trial were offered postnatal care at home by community midwives. The intervention group were also offered 10 visits from a support worker for up to three hours per day in the first 28 postnatal days.

Outcomes and follow up-Postal follow up questionnaires were issued at six weeks and six months postnatally. The primary outcome measure was the short form-36 (SF-36) general health perception domain measured at six weeks. ${ }^{12}$ Secondary outcomes were the
Medical Care
Research Unit,
School of Health
and Related
Research
(ScHARR),
University of
Sheffield, Sheffield
S1 4DA
C Jane Morrell
research fellow
Obstetrics and
Gynaecology
Management,
Northern General
Hospital, Sheffield
S5 7AU
Helen Spiby
research and
development midwife
P Stewart
clinical director of
obstetrics and
gynaecology
Sheffield Health
Economics Group,
ScHARR,
University of
Sheffield
S Walters
statistician
A Morgan
research associate
Correspondence to:
C J Morrell
J.Morrell1@
Sheffield.ac.uk
BMJ 2000;321:593-8 


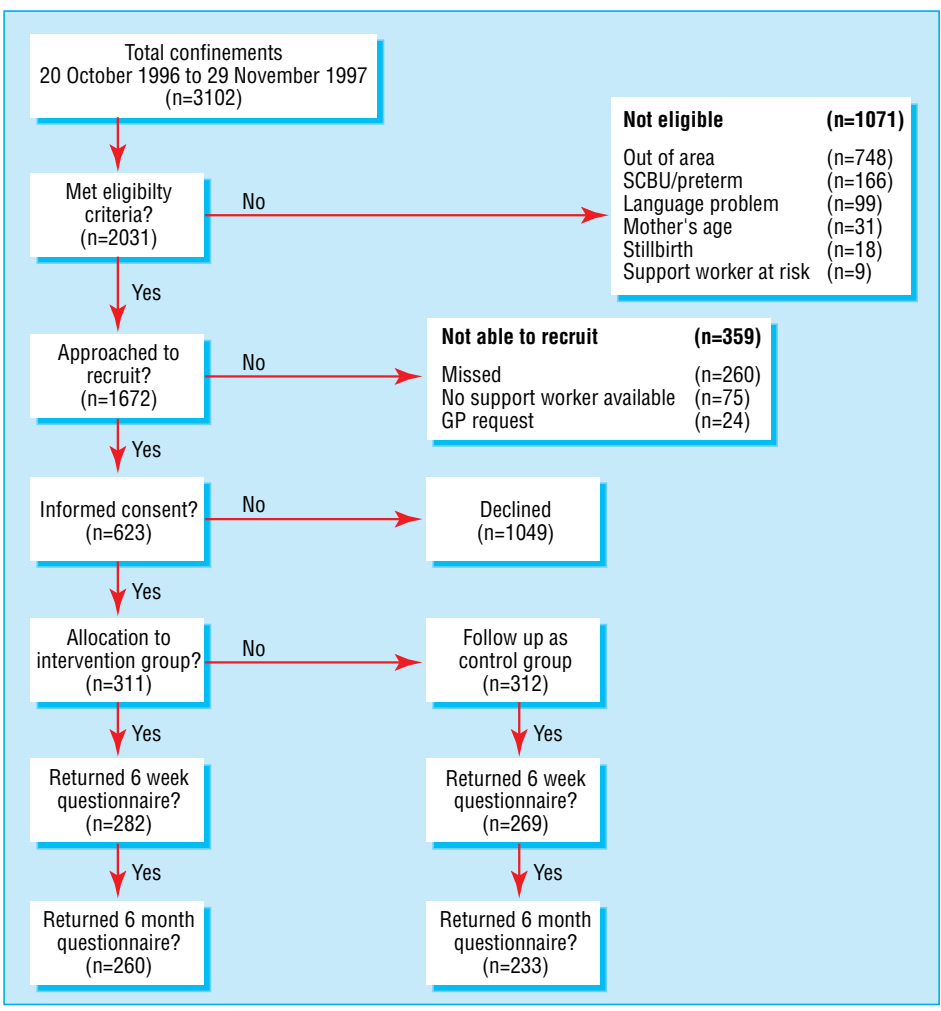

Diagrammatic representation of sample size

other SF-36 domains, the Edinburgh postnatal depression scale, ${ }^{13}$ the Duke functional social support scale, ${ }^{14}$ and breast feeding rates. To have an $85 \%$ chance of detecting as significant (at the two sided 5\% level) a five point difference between the two groups in the mean SF-36 general health perception scores, with an assumed standard deviation of $20.00^{15}$ and a loss to follow up of 20\%, 360 women (720 in total) in each group were required.

Table 1 Recruitment details and socioeconomic characteristics according to allocation to extra postnatal support or control group. Figures are numbers of women unless stated otherwise

\begin{tabular}{lccc} 
& Intervention group & Control group & P value $^{*}$ \\
\hline Mean (SD) age (years) & $27.5(5.8)$ & $28.0(5.7)$ & $0.33 \dagger$ \\
\hline Mean (SD) birth weight (grams) & $3443.8(544.6)$ & $3435.2(475.5)$ & $0.83 \dagger$ \\
\hline Mean (SD) parity & $1.9(1.1)$ & $1.8(1.0)$ & $0.78 \ddagger$ \\
\hline Spontaneous onset of labour & $212 / 311$ & $228 / 312$ & 0.21 \\
\hline Twin birth & $9 / 311$ & $1 / 312$ & $0.01 \S$ \\
\hline Elective caesarean section & $25 / 311$ & $24 / 312$ & 0.87 \\
\hline Emergency caesarean section & $30 / 311$ & $32 / 312$ & 0.80 \\
\hline Used TENS machine & $38 / 311$ & $21 / 312$ & 0.02 \\
\hline General anaesthetic & $12 / 311$ & $6 / 312$ & 0.15 \\
\hline Receiving housing benefit & $90 / 305$ & $89 / 305$ & 0.93 \\
\hline Owner occupier (mortgage) & $174 / 310$ & $172 / 311$ & 0.65 \\
\hline Rented (local authority/council) & $103 / 310$ & $109 / 311$ & 0.38 \\
\hline Central heating in home & $282 / 306$ & $287 / 308$ & 0.65 \\
\hline Car available for use & $244 / 311$ & $236 / 310$ & 0.38 \\
\hline $\begin{array}{l}\text { Paid job in past 6 months } \\
\text { One or more children under 16 living } \\
\text { with mother }\end{array}$ & $188 / 309$ & $185 / 303$ & 0.78 \\
\hline $\begin{array}{l}\text { One or more adults aged 18 and over } \\
\text { living with mother }\end{array}$ & $166 / 311$ & $181 / 311$ & 0.23 \\
\hline Enough room in home & $269 / 309$ & $244 / 307$ & 0.01 \\
\hline TEN & & $296 / 308$ & 0.19 \\
\hline
\end{tabular}

TENS=transcutaneous electrical nerve stimulation.

*All from $\chi^{2}$ test, except $\dagger t$ test, $\ddagger$ Mann-Whitney test, $\S$ Fisher’s exact test.
Statistical analysis-All analyses were completed on an intention to treat basis. Demographic and clinical data were compared between the two groups. The health status scores (SF-36, Edinburgh postnatal depression scale, Duke functional social support scale) were assumed to be continuous measurements and were compared with $t$ test or Mann-Whitney $\mathrm{U}$ test. For categorical data we used $\chi^{2}$ test or Fisher's exact test. We estimated non-parametric bootstrap centile confidence intervals for the difference in mean scores between the groups. ${ }^{16}$

Assignment-Individual women were randomly allocated to intervention or control group with sequentially numbered, sealed opaque envelopes. The allocation schedule was prepared in advance by using random digit tables. The process achieved a balanced randomisation and concealed the group of allocation from all parties until after recruitment.

Economic analysis-The aim of the economic evaluation was to compare costs and outcomes at six weeks and at six months after delivery. All costs were identified, measured, and valued from an NHS perspective. Secondary analysis compared use of social services and personal expenditure. The support workers and midwives recorded the number of their visits to each woman. Visit costs were estimated by multiplying the duration of the visit in minutes by salary per minute. Women reported contacts with general practitioners, health visitors, hospitals, and mental health services and use of social services and personal expenditure. We used data on local costs to value all resources except contact with general practitioners, health visitors, and social services, which were valued using national estimates. ${ }^{17}$

\section{Results}

Recruitment-We recruited 623 women: 311 intervention, 312 control (figure). There were no significant differences between groups in 26 birth details or 88 socioeconomic details, except for incidence of twins, use of transcutaneous electrical nerve stimulation (TENS) machines during labour, and adults living with the mother (table 1). There was a one year mean difference in age between the recruited women and those who declined to take part $(95 \%$ confidence interval 0.5 to 1.6), though this difference was not clinically important. The women who consented to take part were more likely to be white $(\mathrm{P}=0.001)$ and to have had an elective caesarean section $(\mathrm{P}=0.02)$, suggesting some self selection among women who perceived the need for additional support. The most commonly reported reason for not taking part was the availability of other help at home.

Intervention-Most women received six visits from a support worker, and $48(15 \%)$ received 10 visits. Thirty eight women (12\%) declined all visits but were included in the follow up and analysis. The length of visits ranged from 10 to 375 minutes, with most time spent on housework (38\%), talking with the mother $(23 \%)$, dealing with the baby $(9 \%)$, dealing with other siblings $(8 \%)$, bottle feeding $(7 \%)$, talking about the baby $(6 \%)$, and discussing breast feeding $(3 \%)$. 
Table 2 Health outcomes measured at six weeks according to allocation to extra postnatal support or control group. Figures are means (SD) scores* unless stated otherwise

\begin{tabular}{|c|c|c|c|c|c|c|}
\hline & \multicolumn{2}{|c|}{ Intervention } & \multicolumn{2}{|c|}{ Control } & \multirow[b]{2}{*}{ Mean difference $(95 \% \mathrm{CI})$} & \multirow{2}{*}{$\begin{array}{l}P \text { value for } \\
\text { difference }\end{array}$} \\
\hline & No of women & Mean (SD) & No of women & Mean (SD) & & \\
\hline SF-36 general health perception & 276 & $75.1(18.4)$ & 263 & $76.7(18.6)$ & $-1.6(-4.7$ to 1.4$)$ & 0.22 \\
\hline Physical functioning & 278 & $86.9(16.0)$ & 265 & $89.1(15.4)$ & $-2.2(-4.6$ to 0.5$)$ & 0.01 \\
\hline Social functioning & 281 & $76.4(24.1)$ & 268 & $80.2(23.8)$ & $-3.8(-7.7$ to 0.3$)$ & 0.03 \\
\hline Role limitation-physical & 275 & $65.2(39.4)$ & 260 & $73.2(38.8)$ & $-7.9(-14.6$ to 0.9$)$ & 0.008 \\
\hline Role limitation-emotional & 275 & $77.3(35.3)$ & 259 & $77.4(36.6)$ & $-0.1(-6.5$ to 6.1$)$ & 0.77 \\
\hline Mental health & 282 & $72.0(17.5)$ & 268 & $72.7(17.8)$ & $-0.7(-3.8$ to 2.2$)$ & 0.60 \\
\hline Vitality & 282 & $49.7(21.3)$ & 268 & $50.3(20.9)$ & $-0.6(-4.1$ to 3.0$)$ & 0.81 \\
\hline Pain & 282 & $70.7(24.3)$ & 268 & $73.8(24.9)$ & $-3.0(-6.9$ to 1.1$)$ & 0.08 \\
\hline Health change & 282 & $63.9(26.1)$ & 269 & $65.6(26.2)$ & $-2.0(-6.0$ to 3.2$)$ & 0.39 \\
\hline Duke functional social support & 260 & $16.7(6.7)$ & 253 & $16.6(7.4)$ & $0.0(-1.3$ to 1.3$)$ & 0.63 \\
\hline Edinburgh postnatal depression scale & 276 & $7.4(5.2)$ & 266 & $6.7(5.5)$ & $0.7(-0.2$ to 1.6$)$ & 0.05 \\
\hline No who breastfed only & 280 & 87 & 268 & 72 & & $0.55 \S$ \\
\hline No who formula fed only & 280 & 154 & 268 & 155 & & \\
\hline No who used mixed feeding & 280 & 39 & 268 & 41 & & \\
\hline
\end{tabular}

${ }^{*}$ For all measures higher scores indicate better health except for Duke functional support scale and Edinburgh postnatal depression scale, when higher scores indicate poorer health.

†All P values are from Mann-Whitney test, which compares distributions of two groups, except $\xi \chi^{2}=1.21$ on $2 \mathrm{df}, \mathrm{P}=0.55$. Bootstrap $95 \%$ confidence intervals (CI) calculated for characteristic of distributions (for example, mean difference) by centile method. Groups may have differences in distributions but similar characteristics (for example, means)

\section{Outcome at six weeks}

Health status-At six weeks $551 \quad(88.4 \%)$ women returned their questionnaire, with a 93\% minimum completion for all the main outcomes. There was no evidence of a difference between the two groups in the primary outcome (table 2). There was evidence of a difference in physical functioning, social functioning, and scores for physical role limitation, indicating better self perceived health in the control group. There was some evidence of a difference in mean scores on the Edinburgh postnatal depression scale in favour of the control group $(\mathrm{P}=0.05)$. There was no evidence of a difference in scores on the Duke functional social support scale or rates of breast feeding between the two groups.

Satisfaction with services-There was a high level of satisfaction with the support worker service, which fulfilled a range of needs, but no difference between groups in satisfaction with their midwife, health visitor, and general practitioner. More women in the intervention group reported that their partner was supportive $(\mathrm{P}=0.04)$.
NHS resource use and costs-There were no significant differences between the two groups in resource use or costs for any NHS service for which data were collected, except for the support worker service. The difference in mean total NHS costs per woman of $£ 179.58$ (table 3 ) was mainly because of the additional costs of providing the support worker service to the intervention group. This cost difference was significant $(\mathrm{P}=0.001)$.

\section{Outcome at six months}

Health status measures-At six months 493 (79.1\%) women returned their questionnaire. There was no evidence of differences in health status scores (SF-36, Edinburgh postnatal depression scale, and Duke functional social support scale) and rates of breast feeding between the two groups (table 4).

Costs of the support worker service-On average women received six visits from support workers, who spent 143 minutes per visit (median 150 minutes) and 24 minutes on travel and administration. Visit costs comprised staff time (84\%), travel expenses $(8 \%)$,

Table 3 NHS resource use and costs at six weeks according to allocation to extra postnatal support or control group. Figures are means (SD) and costs are estimated at 1996 prices

\begin{tabular}{|c|c|c|c|c|c|c|c|c|}
\hline \multirow[b]{2}{*}{ Resource } & \multicolumn{4}{|c|}{ Quantity of resource used } & \multicolumn{4}{|c|}{ Cost of resouce used (£) } \\
\hline & Intervention & Control & Mean difference $(95 \% \mathrm{Cl})$ & $P$ value ${ }^{*}$ & Intervention & Control & Mean difference $(95 \% \mathrm{Cl})$ & $P$ value ${ }^{\star}$ \\
\hline Visitis by support worker† & $5.8(3.3)$ & 0 & & & $160.4(97.6)$ & 0 & & \\
\hline Visits by community midwife & $8.1(1.9)$ & $8.0(1.8)$ & $0.01(-0.27$ to 0.33$)$ & 0.67 & $193.3(52.8)$ & $191.1(55.8)$ & $2.12(-5.96$ to 10.54$)$ & 0.97 \\
\hline Visits by health visitor & $2.4(1.2)$ & $2.4(1.3)$ & $-0.04(-0.24$ to 0.17$)$ & 0.59 & $105.4(51.7)$ & $107.2(49.2)$ & $-1.84(-11.09$ to 7.96$)$ & 0.59 \\
\hline Child health clinic visits & $1.0(0.0)$ & $1.0(0.0)$ & 0.00 (0.001 to 0.001$)$ & 1.00 & $7.7(0.0)$ & $7.7(0.0)$ & 0.00 (0.001 to 0.001$)$ & 1.00 \\
\hline GP contacts for baby & $2.3(1.7)$ & $2.2(1.8)$ & $0.07(-0.22$ to 0.36$)$ & 0.57 & $41.6(31.7)$ & $39.3(31.7)$ & $2.38(-2.64$ to 7.43$)$ & 0.28 \\
\hline GP contacts for self & $1.6(1.5)$ & $1.5(1.5)$ & $0.11(-0.13$ to 0.36$)$ & 0.53 & $29.5(31.5)$ & $28.1(30.0)$ & $1.50(-3.76$ to 6.70$)$ & 0.77 \\
\hline GP prescriptions for baby & $0.8(0.9)$ & $0.9(1.0)$ & $0.10(-0.27$ to 0.06$)$ & 0.27 & $1.2(2.0)$ & $1.8(4.5)$ & $-0.53(-1.17$ to -0.02$)$ & 0.24 \\
\hline GP prescriptions for self & $0.7(1.0)$ & $0.7(0.9)$ & $0.04(-0.12$ to 0.20$)$ & 0.90 & $2.3(8.4)$ & $2.7(7.1)$ & $-0.41(-1.64$ to 0.90$)$ & 0.64 \\
\hline Hospital contactsł for baby & $0.3(0.9)$ & $0.3(0.8)$ & $-0.01(-0.16$ to 0.14$)$ & 0.38 & $68.4(269.4)$ & $51.3(185.6)$ & 17.25 (-24.05 to 58.15$)$ & 0.44 \\
\hline Hospital contactsł for self & $0.2(0.6)$ & $0.1(0.5)$ & $0.05(-0.04$ to 0.14$)$ & 0.18 & $24.2(95.0)$ & $24.6(124.0)$ & $-0.44(-20.80$ to 17.28$)$ & 0.19 \\
\hline Secondary mental health contacts§ & $0.0(0.3)$ & $0.1(0.4)$ & $-0.02(-0.09$ to 0.03$)$ & 0.38 & $1.0(12.1)$ & $2.0(19.5)$ & $-1.07(-4.05$ to 1.52$)$ & 0.38 \\
\hline Total cost & & & & & $635.0(325.5)$ & $456.0(291.3)$ & 179.58 (125.85 to 232.34 ) & 0.001 \\
\hline
\end{tabular}

*All P values are from Mann-Whitney test, which compares distributions of two groups. Bootstrap confidence intervals calculated for characteristic of distributions (for example, mean difference) by centile method. Groups may have differences in distributions but similar characteristics (for example, means).

†Mean number of visits from support worker differ from other figures as some women received no visits.

$\ddagger$ Hospital contacts: inpatient stays, day patient attendances, outpatient attendances, and accident and emergency attendances.

$\S S e c o n d a r y ~ m e n t a l$ health contacts: inpatient, outpatient, community psychiatric nurse, occupational therapists, and consultant contacts. 
Table 4 Health outcomes measured at six months according to allocation to extra postnatal support or control group. Figures are mean (SD) scores* unless stated otherwise

\begin{tabular}{|c|c|c|c|c|c|c|}
\hline & Inte & tion & & & & \\
\hline & No of women & Mean (SD) & No of women & Mean (SD) & Mean difference $(95 \% \mathrm{CI})$ & $\mathrm{P}$ value \\
\hline SF-36 physical functioning & 258 & $89.8(16.8)$ & 230 & $91.2(15.1)$ & $-1.5(-1.2$ to 4.2$)$ & 0.23 \\
\hline Social functioning & 257 & $83.6(22.0)$ & 233 & $84.0(23.6)$ & $-0.4(-4.7$ to 4.0$)$ & 0.36 \\
\hline Role limitation-physical & 259 & $80.2(32.5)$ & 229 & $82.1(32.6)$ & $-1.9(-7.2$ to 3.5$)$ & 0.34 \\
\hline Role limitation-emotional & 257 & $82.4(31.7)$ & 228 & $79.5(35.5)$ & $2.8(-3.4$ to 8.3$)$ & 0.57 \\
\hline Mental health & 254 & $72.8(17.3)$ & 227 & $74.0(17.5)$ & $-1.2(-4.3$ to 1.8$)$ & 0.30 \\
\hline Vitality & 252 & $56.1(21.1)$ & 228 & $54.7(21.3)$ & $1.4(-2.5$ to 5.1$)$ & 0.49 \\
\hline Pain & 256 & $81.0(22.7)$ & 232 & $82.8(23.2)$ & $-1.9(-5.8$ to 2.2$)$ & 0.22 \\
\hline General health perception & 255 & $76.0(19.4)$ & 230 & $76.9(20.4)$ & -0.9 ( -4.5 to 2.7$)$ & 0.38 \\
\hline Health change & 259 & $67.4(23.0)$ & 232 & $64.8(24.2)$ & $2.6(-1.6$ to 6.7$)$ & 0.26 \\
\hline Duke functional social support & 240 & $17.1(6.8)$ & 225 & $16.7(7.3)$ & $0.4(-0.9$ to 1.8$)$ & 0.29 \\
\hline Edinburgh postnatal depression scale & 252 & $6.6(5.1)$ & 229 & $6.7(5.6)$ & $-0.1(-1.0$ to 1.9$)$ & 0.73 \\
\hline No who breast fed only & 260 & 33 & 233 & 28 & & $0.86 \S$ \\
\hline No who fed formula milk only & 260 & 208 & 233 & 185 & & \\
\hline No who mixed feeding & 260 & 19 & 233 & 20 & & \\
\hline
\end{tabular}

${ }^{*}$ For all measures higher scores indicate better health except for Duke functional social support and Edinburgh postnatal depression scale where higher scores indicate poorer health.

$\dagger$ All $P$ values are from Mann-Whitney test, which compares distributions of two groups, except $\S \chi^{2}=0.30$ on $2 \mathrm{df}, \mathrm{P}=0.86$. Bootstrap $95 \%$ confidence intervals calculated for characteristic of distributions (for example, mean difference) by centile method. Groups may have differences in distributions but similar characteristics (for example, means).

education and training (5\%), and equipment (3\%). The mean (SD) cost per support worker visit was $£ 27.70$ (£6.20). The mean (SD) cost per woman who received the visits was $£ 179.30$ ( $£ 83.30$ ). The total cost of the support worker service provided was $£ 48960$.

NHS resource use and costs-At six months there were no significant differences between the groups in NHS resource use except for the support worker service. The mean (SD) total NHS cost for the intervention group was $£ 815.20$ ( $£ 564.70$ ) and for the control group was $£ 638.9$ ( $£ 500.40)$. The mean difference in total NHS costs between the groups was $£ 178.61$ (95\% confidence interval $£ 79.60$ to £272.40) (table 5).

\section{Discussion}

The trial was established to assess whether there were any positive outcomes for the women in the intervention group. The data indicate no improvements in health status for these women for any measures used. There was even an indication that some domains of health status in the intervention group may have worsened in relation to the control group.
As is typical of trials, the participants were self selected, but the only significant difference between the women who were recruited and those who declined to take part was a one year difference in mean age, which seems of little importance to health outcomes. There were very good rates of response and completion in those recruited. Although by chance more women with twins were recruited to the intervention group, the outcomes for these few women were no poorer than for all the other women.

\section{Outcome measures}

The generic SF-36 may have been too insensitive to detect change or distinguish differences in outcomes between the groups. Nevertheless, the trial had over $80 \%$ power to detect a 5 point difference in general health perception scores, which is the smallest change in score considered "clinically and socially relevant."12 When we planned the trial we could not find any measures for evaluating women's experiences of motherhood. Further research is needed to establish the outcomes that mothers themselves value.

Table 5 NHS resource use and costs at six months according to allocation to extra postnatal support or control group. Figures are means (SD) and costs are estimated at 1996 prices

Quantity of resource used

Resource

Visits by support worker†

Visits by community midwife

Visits by health visitor

Child health clinic visits

GP contacts for baby

GP contacts for self

GP prescriptions for baby

GP prescriptions for self

Hospital contacts $\ddagger$ for baby

Hospital contactsł for self

Secondary mental health contacts

Total cost

Intervention Control Mean difference $(95 \% \mathrm{Cl}) \quad$ P value $^{\star}$

*All P values are from Mann-Whitney test, which compares distributions of two groups. Bootstrap confidence in
by centile method. Groups may have differences in distributions but similar characteristics (for example, means).

†Mean number of visits from support worker differ from other figures as some women received no visits.

$\ddagger$ Hospital contacts: inpatient stays, day patient attendances, outpatient attendances, and accident and emergency attendances

§Secondary mental health contacts: inpatient, outpatient, community psychiatric nurse, occupational therapists, and consultant contacts.
Cost of resouce used $(\xi)$

\begin{tabular}{cccc}
\hline Intervention & Control & Mean difference $\mathbf{( 9 5 \% ~ C I )}$ & P value $^{*}$ \\
\hline $160.2(97.6)$ & 0 & & \\
\hline $192.7(53.0)$ & $190.7(49.2)$ & $1.99(-7.60$ to 11.30$)$ & 0.91 \\
\hline $104.9(49.1)$ & $1060.0(56.2)$ & $-1.46(-11.38$ to 7.87$)$ & 0.93 \\
\hline $7.7(0)$ & $7.7(0)$ & $0.001(0.001$ to 0.001$)$ & 1.0 \\
\hline $68.4(45.0)$ & $64.4(44.8)$ & $3.77(-4.45$ to 11.79$)$ & 0.20 \\
\hline $39.8(37.9)$ & $43.8(43.0)$ & $-4.09(-11.03$ to 3.09$)$ & 0.29 \\
\hline $4.3(6.0)$ & $5.2(9.8)$ & $-0.94(-2.5$ to 0.42$)$ & 0.98 \\
\hline $5.9(14.5)$ & $9.4(22.0)$ & $-3.70(-7.45$ to -0.20$)$ & 0.06 \\
\hline $170.5(485.1)$ & $140.0(367.8)$ & $31.76(-45.86$ to 110.63$)$ & 0.73 \\
\hline $54.4(157.5)$ & $59.3(231.5)$ & $-4.66(-46.60$ to 29.75$)$ & 0.52 \\
\hline $6.5(54.0)$ & $11.9(69.3)$ & $-5.35(-16.51$ to 5.21$)$ & 0.41 \\
\hline $815.2(564.7)$ & $638.9(500.4)$ & $178.61(79.60$ to 272.40$)$ & 0.001 \\
\hline
\end{tabular}

0.001 
What is already known on this topic

Previous work has indicated that additional postnatal support could improve wellbeing, reduce the risk of postnatal depression, and improve rates of breast feeding

\section{What this study adds}

Women valued and were highly satisfied with the additional postnatal support from the support worker service

There was no difference in health status between groups for the primary outcome and no improvement in self perceived health status in the intervention group with the SF-36, Edinburgh postnatal depression scale, or Duke functional support scale or in rates of breast feeding

There was little difference between groups in use of NHS services and costs, but there was an additional cost for the support worker service

The six week evaluation time point was selected because the Edinburgh postnatal depression scale is validated for use at this time ${ }^{13}$ and to allow comparisons with results of other trials. Because the support worker visits ended at four weeks, however, the outcomes in the intervention group may be explained by women experiencing a positive effect while the intervention was in progress and a withdrawal effect when it ceased.

A trial that monitored an intervention of a stroke family worker also found no improvement in physical outcomes for carers or patients, who tended to be more helpless and possibly depressed..$^{18}$ The authors suggested that the support induced a passive response instead of improving patients' coping skills. A similar process could have operated here, whereby women in the control group quickly mobilised their available support, which continued to operate at six weeks. For women in the intervention group the support worker's presence may have disrupted this mobilisation of support and coping mechanisms so that at six weeks they were coping less well than women in the control group.

\section{Satisfaction with support worker service}

More than $75 \%$ of women in the intervention group thought the support worker service was better than expected, and some indicated that women could be charged for the service. A subsequent study on willingness to pay could place a financial value on the intangible benefits of the service. ${ }^{19}$ Some women would have preferred the intervention to have lasted longer, perhaps six weeks, which may have provided more enduring benefits.

The perception of greater support from the partners of women in the intervention group echoes the findings of a trial of social support provided by a research midwife in pregnancy. ${ }^{20}$ It found an enduring effect of support from partners in child care and with housework, shopping, and cooking. ${ }^{21}$ There may also be long term positive effects of antenatal and early postnatal home visits for first time young mothers.2. ${ }^{23}$

The results did not fully correspond with earlier positive findings of the impact of community based support on rates of breast feeding. ${ }^{24}$ Our trial was not powered to detect significant differences in rates of breast feeding and use of secondary mental health or other services. The wider public health implications of such outcomes could not be explored within the trial.

\section{Economic evaluation}

There was no evidence that women receiving the support worker service used fewer NHS services than those receiving standard care at either six weeks or six months. The incremental cost of introducing a support worker service would therefore comprise mainly the costs of setting up and running the service. The main issue of uncertainty surrounds the cost of the developing service, which could be expected to evolve over time. We therefore used the sensitivity analysis to explore the cost implications of an increased throughput for the service. By limiting each visit to 120 minutes, with each support worker making a minimum of three visits a day, total costs per woman could be reduced from $£ 179$ to $£ 151$. By imposing these restrictions, however, the support workers would be unlikely to achieve their objectives because of lack of time.

We are grateful to all the women who participated in the trial, and we thank the support workers and are grateful for thei contribution. We acknowledge the important contribution of the trial research midwife, Sue Crowther.

Contributors: CJM was the principal investigator, was responsible for the design and execution of the study, coordinated the formulation of the research hypothesis and the protocol design, participated in recruitment of women to the trial, and participated in the collection, management, analysis, and interpretation of the data and writing of the paper. HS initiated the research, discussed core ideas, contributed to the development of the primary study hypothesis, participated in the protocol design and recruitment of women to the trial, and participated in data collection, analysis, and interpretation of the data and writing of the paper. PS initiated the research, discussed core ideas, contributed to the development of the primary study hypothesis, and participated in the protocol design, interpretation of the data, and writing of the paper. SW prepared the calculation of sample size and the random allocation schedule, performed the recruitment monitoring, and participated in the analysis and interpretation of the data and writing of the paper. AM participated in the analysis and interpretation of the data and writing of the paper. CJM is the guarantor.

Funding: This trial was prioritised, commissioned, and funded by the NHS Research and Development, Health Technology Assessment programme. The views expressed are those of the authors and not necessarily those of the commissioning board of the programme.

Competing interests: None declared.

1 Bick D, MacArthur C. The extent, severity and effect of health problems after childbirth. Br J Midwifery 1995;3:27-31.

2 Murray L. The impact of postnatal depression on infant development J Child Psychol Psychiatry 1992;33:543-61.

3 Glazener CMA, MacArthur C, Garcia J. Postnatal care: time for change. Contemp Rev Obstet 1993;5:130-6.

4 Montgomery E, Alexander J. Assessing postnatal uterine involution: a review and a challenge. Midwifery 1994;5:9-12.

5 Kumar R, Marks M, Jackson K. Prevention and treatment of postnatal psychiatric disorders. Br J Midwifery 1995;3:314-7.

6 Audit Commission. First class delivery: improving maternity services in England and Wales. London: Audit Commission, 1997

7 Cohen S, Syme SL. Social support and health. Orlando: Harcourt Brace Jovanovich, 1985

8 Elbourne D, Oakley A, Chalmers I. Social and psychological support during pregnancy. In: Chalmers I, Enkin M, Keirse MJNC. Effective care in pregnancy and childbirth. Oxford: Oxford University Press, 1989:221-36.

9 Matich JR, Sims LS. A comparison of social support variables between women who intend to breast or bottle feed. Soc Sci Med 1992;34:919-27.

10 Ray KL, Hodnett ED. Caregiver support for postpartum depression. In Cochrane Collaboration. Cochrane Library. Issue 1. Oxford: Update Software, 2000.

11 Spiby H, Crowther S. Dutch maternity aides: a transferable model? $R C M$ Midwives J 1999;2:20-1. 
12 Ware J, Sherbourne C. The MOS 36 item short-form health survey (SF36). Med Care 1992;30:473-83.

13 Cox JL, Holden J, Sagovsky R. Detection of postnatal depression: development of the 10-item Edinburgh postnatal depression scale (EPDS). Br J Psychiatry 1987;150:782-6.

14 Broadhead WE, Gehlbach SH, De Gruy FV, Kaplan BH. The Duke-UNC functional social support questionnaire measurement of social support in family medicine patients. Med Care 1988;26:709-23.

15 Brazier JE, Harper R, Jones NMB, O'Cathain A, Thomas KJ, Usherwood $\mathrm{T}$, et al. Validating the SF-36 health survey questionnaire: new outcome measures for primary care. BMJ 1992;306;1407-40.

16 Efron B, Tibishirani RJ. An introduction to the bootstrap. New York: Chapman and Hall, 1993.

17 Netten A, Dennett J. Unit costs of health and social care. Canterbury: University of Kent, Personal Social Services Research Unit, 1997.

18 Dennis M, O'Rourke S, Slattery J, Staniforth T, Warlow C. Evaluation of a stroke family care worker: results of a randomised controlled trial. BMJ 1997;314:1071-6.
19 Drummond M, O'Brien B, Stoddart G. Torrence GW. Methods for the economic evaluation of health care programmes. Oxford: Oxford Universit Press, 1997.

20 Oakley A, Rajan L, Grant A. Social support and pregnancy outcome. $\mathrm{Br} J$ Obstet Gynaecol 1990;97:155-62.

21 Oakley A, Hickey D, Rajan L. Social support in pregnancy: does it have long-term effects? J Reprod Infant Psychol 1996;14:7-22

22 Olds DL, Eckenrode J, Henderson CR, Kitzman H, Powers J, Cole R, et al. Long-term effects of home visitation on maternal life course and child abuse and neglect. JAMA 1997;278:637-43.

23 Kitzman H, Olds DL, Henderson CR, Hanks C, Cole R, Tatelbaum R, et al. L Effect of prenatal and infancy home visitation by nurses on pregnancy outcomes, childhood injuries, and repeated childbearing JAMA 1997:278:644-52

24 Houston MJ, Howie PW, Cook A. Do breast feeding mothers get the home support they need? Health Bull 1981;39:166-72.

(Accepted 18 May 2000)

\section{Cohort study of risk of fracture before and after surgery for primary hyperparathyroidism}

Peter Vestergaard, Charlotte L Mollerup, Vibe Gedsø Frøkjær, Peer Christiansen, Mogens Blichert-Toft, Leif Mosekilde

Department of Endocrinology and Metabolism, Aarhus University Hospital, Aarhus

Amtssygehus,

Aarhus, Denmark

Peter Vestergaard

research associate

Leif Mosekilde

professor of internal

medicine

Department of

Endocrine Surgery,

Rigshospitalet,

Copenhagen,

Denmark

Charlotte L

Mollerup

consultant in surgery

Vibe Gedsø Frøkjær

medical student

Mogens

Blichert-Toft

professor of surgery

Department of

Surgery, Aarhus

University Hospital

Peer Christiansen

consultant in surgery

Correspondence to:

$P$ Vestergaard,

Osteoporosis Clinic,

Aarhus

Amtssygehus, Tage

Hansens Gade 2,

DK-8000 Århus C,

Denmark

p-vest@post4.

tele.dk

BMJ 2000;321:598-602

\begin{abstract}
Objectives To study whether fracture risk before and after surgery was increased in patients with primary hyperparathyroidism.

Design Cohort study.

Setting Three Danish university hospitals.

Participants 674 consecutive patients with primary hyperparathyroidism (median age 61, range 13-89 years) operated on during the period 1 January 1979 to 31 December 1997; 2021 age and sex matched controls from national patient register.

Main outcome measure Fractures.

Results The cases had an increased relative rate of fractures compared with the controls before surgery $(1.8,95 \%$ confidence interval 1.3 to 2.3$)$ but not after surgery (1.0, 0.8 to 1.3). The risk of fracture was increased for the vertebrae (3.5, 1.3 to 9.7), the distal part of the lower leg and ankles (2.3, 1.2 to 4.3$)$, and the non-distal part of the forearm (4.0, 1.5 to 10.6) before surgery but not after. The increase in risk of fracture began about 10 years before surgery. Risk peaked 5-6 years before surgery and remained raised, although at a lower level, in the five years immediately before surgery. A small increase in risk of fracture of the distal forearm emerged more than 10 years after surgery $(2.9,1.3$ to 6.7$)$.
\end{abstract}

Conclusions Risk of fracture is increased up to 10

years before surgery in patients with primary

hyperparathyroidism. The risk returns to normal after surgery.

\section{Introduction}

Several studies have shown decreased bone mineral content or density in patients with primary hyperparathyroidism. ${ }^{12}$ The reduction varied between skeletal regions, ${ }^{1}$ generally tending towards a higher degree of cortical than trabecular bone loss. After surgical cure of primary hyperparathyroidism, the bone mineral density increases over the first few years in both the forearm ${ }^{3-5}$ and the lumbar spine. ${ }^{56}$ Although a deficit in bone mineral density in the forearm seems to remain, ${ }^{3}$ spinal bone mineral density is usually restored ${ }^{67}$ Long term studies have found a permanent decrease in bone mineral density of the forearm in patients who had ${ }^{7} 8$ and had not ${ }^{9}$ had surgery. A follow up study comparing patients who had had surgery with patients who had not had surgery, showed no difference in forearm bone mineral content after 17 years despite an initial increase in forearm bone mineral content after surgery. ${ }^{3}$ Both groups had lower forearm bone mineral content than control subjects. ${ }^{3}$

Decreased bone mineral density increases the risk of fracture. Several studies have reported an increased prevalence of fractures in patients at the time of diagnosis of primary hyperparathyroidism. ${ }^{10-13}$ The sites at which risk of fracture is increased are the forearm, ${ }^{12}{ }^{13}$ the spine, ${ }^{12}{ }^{14}$ and the femoral neck. ${ }^{12}$ Melton et al reported an increase in fracture risk before, but not after, diagnosis of primary hyperparathyroidism. ${ }^{11}$ In contrast, a large cohort study found no increased risk of hip fractures. ${ }^{15}$ Wilson et al also found no increased risk of vertebral fractures in patients with mild asymptomatic primary hyperparathyroidism. ${ }^{2}$ However, most studies have reported on a limited number of patients ${ }^{10}{ }^{11}$ or have not evaluated the incidence of fracture before and after treatment. ${ }^{10} 12131516$

We conducted a large cohort study in 674 patients who had had surgery for primary hyperparathyroidism at three Danish centres and included 2021 controls to assess the risk of fracture before and after surgery at multiple skeletal sites.

\section{Participants and methods}

A total of 674 patients had had surgery for primary hyperparathyroidism during the period 1 January 1979 to 31 December 1997 at three Danish centres: Rigshospitalet in Copenhagen (1991-7), Aarhus University Hospital (1979-97), and Odense University Hospital (1979-90). The diagnosis was established by 